\title{
EPIDEMIOLOGIA MOLECULAR APLICADA AO MONITORAMENTO DE ESTIRPES DE Staphylococcus aureus NA PRODUÇÃO DE QUEIJO MINAS FRESCAL
}

\author{
Maria IZABel Merino de Medeiros ${ }^{1}$, Antonio NADER Filho ${ }^{2}$, Viviane De SOUZA ${ }^{3}$, Poliana de \\ CAstro MElo $^{3}$, LuCiano MENEZES FERreira ${ }^{4}$, Luis M. MEdina CANAlejo ${ }^{5}$ \\ ${ }^{1}$ Pesquisadora Doutora do Agência Paulista de Tecnologia dos Agronegócios, Instituto de Tecnologia de Alimentos - ITAL, \\ Campinas, SP, Brasil - belvt@uol.com.br \\ ${ }^{2}$ Professor Doutor da Universidade Estadual Paulista Júlio de Mesquita Filho, Jaboticabal, SP. Brasil. \\ ${ }^{3}$ Pesquisadoras Doutoras da Empresa Brasileira de Pesquisa Agropecuária, Embrapa Caprinos e Ovinos, Sobral, CE, Brasil. \\ ${ }^{4}$ Professor Doutor da Universidade Camilo Castelo Branco, Araraquara, SP, Brasil. \\ ${ }^{5}$ Professor Doutor da Universidade de Córdoba, Espanha.
}

Foi realizado o monitoramento epidemiológico molecular de estirpes de Staphylococcus aureus potencialmente toxigênicas isoladas no processo de produção do queijo Minas frescal em micro-usina do Estado de São Paulo. Para tanto, foram realizadas seis amostragens durante o período de junho de 2008 a julho de 2009, de modo a perfazer um total de 140 amostras. Essas amostras foram colhidas da superfície dos tanques de recepção e estocagem do leite cru, da superfície do tanque de equilíbrio do leite pasteurizado, da rede de abastecimento de água, das tubulações e equipamentos, das mãos do manipulador e de queijos embalados prontos para consumo. As colônias isoladas em Agar Baird-Parker confirmadas como cocos Gram positivos e que mostravam-se positivas às provas de catalase, coagulase $\mathrm{e}$ da produção de acetoína, foram submetidas à extração do
DNA bacteriano através da utilização do Kit Invitek Uniscience®. A confirmação molecular da espécie dos isolados e a presença de enterotoxinas SEA, SEB, SEC, SED e da toxina TSST-1 foi realizada a partir da amplificação dos fragmentos de DNA cromossômico específico. Entre as 74 estirpes de estafilococos coagulase positivos isoladas, somente $41(55.4 \%)$ amostras foram confirmadas como sendo Staphylococcus aureus, das quais $25(61,0 \%)$ mostraram-se positivas na pesquisa de toxinas estafilocócicas. A enterotoxina de maior frequência identificada foi a SEA. As estirpes de Staphylococcus aureus toxigênico foram mais isoladas nas mãos do manipulador $(16,0 \%)$, no leite cru do tanque de recepção $(12,0 \%)$, no leite pasteurizado para elaboração do queijo $(12,0 \%)$ e no queijo Minas frescal pronto para consumo $(12,0 \%)$.

PALAVRAS-CHAVE: PCR; queijo Minas frescal; segurança de alimentos; Staphylococcus aureus; toxinas estafilocócicas.

\section{MOLECULAR EPIDEMIOLOGY APPLIED TO MONITORING STRAINS OF Staphylococcus aureus IN MINAS FRESCAL CHEESE PRODUCTION}

\section{ABSTRACT}

We studied the molecular epidemiology of Staphylococcus aureus strains potentially toxigenic, isolated from the production process of Minas frescal cheese in a small dairy plant in the state of São Paulo. For this, samples were taken during the period from June 2008 to July 2009. Samples were collected from the surface of the receiving and storage tanks of raw milk, the surface of the balance tank of pasteurized milk, the water supply system, the pipes and equipments, the hands of the handler and from the packaged cheese, totaling 140 samples. The colonies isolated on Baird-Parker Agar confirmed as Gram positive and positive for catalase, coagulase and acetoin production, were submitted to extraction of bacterial DNA using the Invitek - Uniscience ${ }^{\circledR}$ kit. 
Confirmation of the isolated species and enterotoxins SEA, SEB, SEC, SED and TSST-1 toxin was carried out through the amplification of specific fragments of chromosomal DNA. Among the 74 strains of isolated coagulase-positive staphylococci, only 41 (55.4\%) strains were confirmed as Staphylococcus aureus, of which 25 $(61.0 \%)$ were positive to the presence of staphylococcal toxins. The most frequently identified enterotoxin was SEA. The toxigenic strains of Staphylococcus aureus were more frequently isolated from hands of the handler $(16.0 \%)$, raw milk receiving tank $(12.0 \%)$, pasteurized milk for cheese making $(12.0 \%)$ and fresh white cheese ready for consumption $(12.0 \%)$.

KEYWORDS: food safety; fresh white cheese; PCR; Staphylococcus aureus; staphylococcal toxins.

\section{INTRODUÇÃO}

A segurança de alimentos é essencial para os consumidores e para todos os órgãos responsáveis pela Saúde Pública. O queijo Minas frescal é bastante produzido pela indústria de laticínios, sendo comercializado a preços acessíveis à grande parte da população. É um queijo não maturado, com elevado teor de umidade, sendo susceptível a contaminações bacterianas (QUINTANA \& CARNEIRO, 2007).

O Staphylococcus aureus, por se tratar de um microrganismo patogênico que apresenta uma grande capacidade de adaptação a condições ambientais adversas, representa um importante agente de toxiinfecção alimentar associado muitas vezes ao consumo de queijos (CARMO et al., 2002). Os principais sintomas dessa intoxicação são náuseas, vômito e diarréia, e em idosos, crianças e imunodeprimidos a intoxicação estafilocócica pode ser fatal (BORGES et al., 2008).

$O$ processo de aquecimento utilizado na pasteurização do leite inativa os Staphylococcus, mas não as toxinas previamente produzidas, que permanecem ativas nos alimentos por um longo período (CARMO et al., 2002).

A presença de Staphylococcus nos alimentos é encarada como um indicador de deficiências de carácter higiênico no processo de obtenção do alimento e particularmente nas operações de manipulação (BORGES et al., 2008). Sendo assim, esse produto pode representar um risco à saúde pública se cuidados higiênicos sanitários não forem seguidos com rigor durante o processo de produção.

A caracterização exata dos patógenos se faz imprescindível para a detecção dos locais de contaminação do processamento, além de permitir o monitoramento da disseminação de estirpes bacterianas.

Diante das poucas informações disponíveis sobre a epidemiologia do Staphylococcus aureus na produção do queijo Minas frescal, foi escolhida para estudo uma micro-usina produtora da região centro leste do Estado de São Paulo.

\section{MATERIAL E MÉTODOS}

Estudou-se uma micro usina de beneficiamento, estabelecida há 19 anos na região centro leste do Estado de São Paulo, cujo volume diário de leite beneficiado situava-se em torno de 4.700 litros, oriundos de 21 produtores rurais. A micro-usina possuía um pasteurizador com capacidade para 1.200 litros/hora e, além do beneficiamento do leite, produzia diariamente cerca de 500 litros de bebida láctea e, semanalmente, 200 litros de iogurte, $16 \mathrm{Kg}$ de ricota e $70 \mathrm{Kg}$ de queijo Minas frescal, objeto deste estudo.

A água utilizada para a limpeza e elaboração dos produtos era de um poço semi-artesiano.

A micro-usina estudada era subordinada à fiscalização do SISP e recebia a assistência de um Médico Veterinário como Responsável Técnico. Diariamente eram realizadas, pelo proprietário, após o recebimento da matéria-prima, as provas da redutase, crioscopia, alizarol e teor de cloretos no leite cru.

Foram realizadas seis amostragens durante os meses de junho de 2008 a julho de 2009, perfazendo um total de 140 amostras. Tais amostras foram colhidas da superfície do tanque de recepção, da superfície do tanque de estocagem do leite cru e do tanque de equilíbrio pós-pasteurização, do leite cru, do leite pasteurizado, da água, da porção final das tubulações relacionadas com o processamento, da superfície das formas, tambler e mesa, das mãos do manipulador responsável pela elaboração do queijo e do queijo após serem embalados para comercialização.

As amostras oriundas da porção final das tubulações e superfície de equipamentos relacionados com o processamento do queijo e mãos do manipulador foram semeadas em ágar Baird-Parker com os suabes utilizados nas colheitas e incubadas a $37^{\circ} \mathrm{C}$ por 24 a 48 horas. Em seguida, 3 a 5 colônias características foram semeadas em tubos com ágar nutriente inclinado e incubadas a $37^{\circ} \mathrm{C}$ por 24 horas. Foram preparados, então, esfregaços corados pelo método de Gram e as culturas que apresentaram forma de cocos Gram-positivos agrupados sob a forma de 
cachos de uva foram submetidas às provas de catalase, da coagulase livre e de produção de acetoína (VP) (MAC FADDIN, 1980).

Para a colheita das amostras de leite oriundas dos tanques de armazenamento da matéria-prima antes e depois da pasteurização, realizou-se a homogeneização do leite do tanque acionando-se o agitador por um tempo mínimo de cinco minutos. Após a homogeneização, um volume de $10 \mathrm{~mL}$ foi retirado, com o auxílio de uma concha esterilizada, da parte superior e central do tanque e acondicionado em frasco de vidro esterilizado (BRITO et al., 1998). Todas as amostras foram acondicionadas em caixa de material isotérmico contendo gelo e levadas ao laboratório para isolamento e identificação bacteriana.

Suabes estéreis mergulhados em água peptonada a $0,1 \%$ foram passados nos espaços interdigitais, nos espaços subungueais e sobre as palmas das mãos do manipulador responsável pela elaboração do queijo e, posteriormente, mergulhados nos respectivos tubos. Os suabes acondicionados em água peptonada a $0,1 \%$ foram transportados em caixa de material isotérmico contendo gelo e levados ao laboratório para isolamento e identificação bacteriana.

As amostras de água foram colhidas diretamente das torneiras e mangueiras existentes na micro-usina, após o escoamento por três minutos, com os devidos cuidados de assepsia, em frascos de vidro esterilizados, em quantidade aproximada de $400 \mathrm{~mL}$ (APHA, 2001). As amostras foram diluídas, quando necessário, até a diluição $10^{-3}$ e submetidas à técnica de membrana filtrante (membrana Schleicher e Schuell de $0,45 \mu$ e 47 mm de diâmetro, ref. $n^{\circ} 1794$ 0 ), em sistema de filtro acoplado em kitasato conectado à bomba de vácuo. Inicialmente, foram filtrados $10 \mathrm{~mL}$ da amostra diluída e, posteriormente, $10 \mathrm{~mL}$ da amostra pura. Entre cada amostra foram filtrados $100 \mathrm{~mL}$ de água destilada estéril (APHA, 2001). Para cada amostra foi utilizada uma membrana, a qual foi colocada em placa de petri contendo ágar Baird-Parker. As colônias suspeitas foram avaliadas segundo suas características morfológicas e tintoriais (Mac FADDIN, 1980).

Para a extração de DNA das estirpes isoladas utilizou-se o Kit Invitek®, - Extração de Material Genômico, que continha o protocolo de extração de DNA para bactérias Gram-positivas, as soluções de lise, de extração e de lavagem e colunas de purificação.

A caracterização molecular dos Staphylococcus aureus foi efetuada a partir da amplificação de fragmentos de DNA cromossômico específico para esses microrganismos, de acordo com o protocolo modificado descrito por MARTINEAU et al. (1998) e adaptado por MEDEIROS (2011). Desse modo, apenas as estirpes identificadas genotipicamente por essa técnica como sendo desta espécie foram submetidas aos testes seguintes. As reações compreenderam volume final de $20 \mu \mathrm{L}$ contendo $20 \mathrm{mM}$ Tris- $\mathrm{HCl}(\mathrm{pH} 8,4), 50 \mathrm{mM} \mathrm{KCl}, 2,5$ $\mathrm{mM} \mathrm{MgCl} 2,0,2 \mathrm{mM}$ de cada $d N T P, 0,4 \mu \mathrm{M}$ de cada oligonucleotídeo iniciador (Quadro 2) Sa442-1 (5'AAT CTT TGT CGG TAC ACG ATA TTC TTC ACG- 3') e Sa442-2 (5'- CGT AAT GAG ATT TCA GTA GAT AAT ACA ACA- 3'), e 0,5 U de Taq polimerase em amplificação do tipo host-start. As misturas de PCR foram submetidas à desnaturação, por três minutos, a $94^{\circ} \mathrm{C}$ e, posteriormente, a 30 ciclos de um segundo, a $95^{\circ} \mathrm{C}$, para desnaturação, e 30 segundos, a $55^{\circ} \mathrm{C}$, para pareamento e extensão dos oligonucleotídeos iniciadores. O produto amplificado foi submetido à eletroforese em gel de agarose, em cuba horizontal. Sendo assim, $10 \mu \mathrm{L}$ do produto amplificado foram aplicados em gel de agarose $2 \%$, corado com brometo de etídeo a uma concentração de $50 \mu \mathrm{L} / \mathrm{L}$ e submetido à corrida eletroforética a $120 \mathrm{~V}$ por 90 min. Utilizou-se marcador de peso molecular de 100 pares de bases (pb) (Invitrogen, Brasil), disposto no gel juntamente com todas as amostras analisadas em cada eletroforese, como padrão para o tamanho das bandas de DNA formadas. O tamanho dos segmentos amplificados era de $108 \mathrm{pb}$. As amostras foram extraídas, amplificadas e visualizadas na mesma sequência. A inclusão de um controle negativo foi realizada durante todo o procedimento, para prevenir riscos de resultados falsos positivos em todas as reações. Foi utilizada a ATCC 25923 como cepa controle positiva de Staphylococcus aureus em todas as reações.

Através da amplificação de suas sequências codificadoras, foi pesquisada a presença dos genes de enterotoxinas dos tipos A a D (sea, seb, sec e sed) e da toxina da síndrome do choque tóxico (tsst-1) das estirpes geneticamente comprovadas como Staphylococcus aureus. Segundo protocolo estabelecido por CUNHA et al. (2007), as reações compreenderam volume final de $50 \mu \mathrm{L}$, contendo 20 $\mathrm{mM}$ Tris- $\mathrm{HCl}(\mathrm{pH} \mathrm{8,4),} \mathrm{1,5} \mathrm{mM} \mathrm{MgCl2,} \mathrm{0,2} \mathrm{mM} \mathrm{de}$ cada dNTP, 20 pmol de cada oligonucleotídeo iniciador (Quadro 3) (JOHNSON et al., 1991) Sea-1 (5'- TTG GAA ACG GTT AAA ACG AA) e Sea-2 (5'- GAA CCT TCC CAT CAA AAA CA); Seb-1 (5'- TCG CAT CAA ACT GAC AAA C) e Seb-2 (5'GCA GGT ACT CTA TAA GTG CC); Sec-1 (5'GAC ATA AAA GCT AGG AATTT) e Sec-2 (5'AAA TCG GAT TAA CAT TAT CC); Sed-1 (5'CTA GTT TGG TAA TAT CTC CT) e Sed-2 (5'TAA TGC TAT ATC TTA TAG GG); Tst-1 (5'ATG GCA GCA TCA GCT TGA TA) e Tst-2 (5'TTT CCA ATA ACC ACC CGT TT), 0,5 U de Taq polimerase em amplificação do tipo host-start e utilizados $5 \mu \mathrm{L}$ de DNA de cada estirpe identificada 
genotipicamente como pertencente à espécie Staphylococcus aureus.

As misturas de PCR foram submetidas a um primeiro ciclo de $94^{\circ} \mathrm{C}$ por $4 \mathrm{~min}$, desnaturação a $94^{\circ} \mathrm{C}$ por $2 \mathrm{~min}$, pareamento a $55^{\circ} \mathrm{C}$ por $1 \mathrm{~min}$ e $30 \mathrm{~s} \mathrm{e}$ extensão dos oligonucleotídeos iniciadores a $72^{\circ} \mathrm{C}$ por 1 min e $30 \mathrm{~s}$, seguido por um segundo ciclo de desnaturação a $94^{\circ} \mathrm{C}$ por $2 \mathrm{~min}$, pareamento a $53^{\circ} \mathrm{C}$ por $1 \min$ e $30 \mathrm{~s}$ e extensão a $72^{\circ} \mathrm{C}$ por $1 \min$ e $30 \mathrm{~s}$. No terceiro ciclo, a temperatura de pareamento foi reduzida a $51^{\circ} \mathrm{C}$, seguido por mais 37 ciclos a $94^{\circ} \mathrm{C}$ por $2 \mathrm{~min}, 51^{\circ} \mathrm{C}$ por $1 \mathrm{~min}$ e $30 \mathrm{~s} \mathrm{e} 72^{\circ} \mathrm{C}$ por $1 \mathrm{~min}$ e $30 \mathrm{~s}$. No final dos 40 ciclos, os tubos foram incubados a $72{ }^{\circ} \mathrm{C}$ por 7 min e a $4{ }^{\circ} \mathrm{C}$ até o momento de retirada do termociclador.

Sendo assim, $10 \mu \mathrm{L}$ do produto amplificado foram aplicados em gel de agarose $2 \%$, corado com brometo de etídeo a uma concentração de $50 \mu \mathrm{L} / \mathrm{L}$ e submetido à corrida eletroforética a $150 \mathrm{~V}$ por $1 \mathrm{~h}$ e $30 \mathrm{~min}$. Utilizou-se marcador de peso molecular de 100 pares de bases (pb) (Invitrogen, Brasil), disposto no gel juntamente com todas as amostras analisadas em cada eletroforese, como padrão para o tamanho das bandas de DNA formadas. O produto de eletroforese foi visualizado em aparelho fotodocumentador Gel Doc 2000 - BioRad. Foram tomados os devidos cuidados para evitar-se a contaminação de utensílios e equipamentos de laboratório com o material genético. As amostras foram extraídas, amplificadas e visualizadas na mesma sequência.

\section{RESULTADOS}

Das 140 amostras colhidas nos diversos pontos do processo de elaboração do queijo Minas frescal, foram isoladas e identificadas 74 estirpes de estafilococos coagulase-positivos (Tabela 1) e submetidas à amplificação de fragmentos de DNA cromossômico específico da espécie de Staphylococcus aureus.

Tabela 1. Distribuições das 74 estirpes de estafilococos coagulase positivos de acordo com os pontos de colheita das amostras.

\begin{tabular}{|c|c|c|}
\hline Ponto de colheita em micro-usina estudada & $\begin{array}{l}\mathrm{n} \\
\text { (amostra) }\end{array}$ & $\%$ \\
\hline Superfície do interior do latão de leite recebido dos produtores & $\begin{array}{l}4 \\
(50,51,52,59)\end{array}$ & 5,4 \\
\hline Superfície do tanque de recepção & $\begin{array}{l}7 \\
(10,11,22,31,32,57,58)\end{array}$ & 9,5 \\
\hline Leite cru do tanque de recepção & $\begin{array}{l}11 \\
(1,2,12,13,14,23,33,34,62,63,66)\end{array}$ & 15,0 \\
\hline Superfície do tanque de estocagem & $\begin{array}{l}7 \\
(3,4,24,25,35,36,67)\end{array}$ & 9,5 \\
\hline Leite cru do tanque de estocagem & $\begin{array}{l}7 \\
(5,6,15,16,26,37,38)\end{array}$ & 9,5 \\
\hline Tubulação de saída do pasteurizador & $\begin{array}{l}1 \\
(68)\end{array}$ & 1,3 \\
\hline Superfície do tanque de equilíbrio do leite pasteurizado & $\begin{array}{l}3 \\
(27,28,47)\end{array}$ & 4,0 \\
\hline Leite pasteurizado para elaboração do queijo & $\begin{array}{l}5 \\
(48,49,53,54,60)\end{array}$ & 6,7 \\
\hline Superfície do tambler de elaboração do queijo & $\begin{array}{l}2 \\
(42,56)\end{array}$ & 1,3 \\
\hline Superfície do cortador da massa do queijo & $\begin{array}{l}2 \\
(21,44)\end{array}$ & 2,7 \\
\hline Superfície da mesa utilizada na elaboração do queijo & $(29,30,39,61)$ & 5,4 \\
\hline Mãos do manipulador & $\begin{array}{l}11 \\
(7,8,9,17,18,40,41,55,72,73,74)\end{array}$ & 15,0 \\
\hline Queijo embalado para comercialização & $\begin{array}{l}10 \\
(19,20,43,45,46,64,65,69,70,71)\end{array}$ & 13,5 \\
\hline TOTAL & 74 & $100 \%$ \\
\hline
\end{tabular}


Entre as 74 estirpes de estafilococos coagulase-positivos, o fragmento de DNA cromossômico específico da espécie de Staphylococcus aureus foi amplificado em 41 amostras. Os produtos da reação de amplificação de algumas amostras submetidas à análise molecular para confirmação das estirpes de Staphylococcus aureus estão apresentados na Figura 1.

As distribuições das estirpes de Staphylococcus aureus isoladas de acordo com a origem das amostras estão apresentadas na Tabela 2.

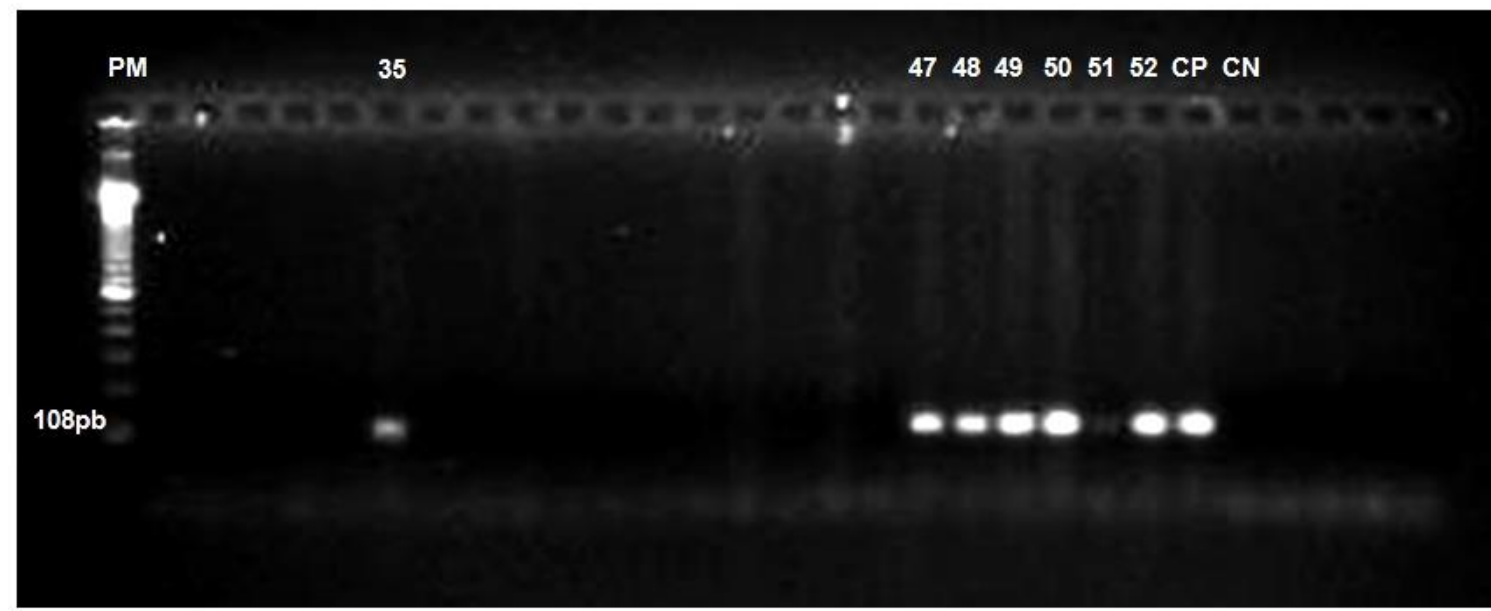

Figura 1. Eletroforograma gerado de amostras submetidas à análise molecular para confirmação das estirpes de Staphylococcus aureus.PM: Marcador de Peso Molecular Ladder 100 (Invitrogen ${ }^{\circledR)}$ ) CP: Controle positivo (utilização de DNA da ATCC 25923);CN: Controle Negativo (utilização de água Mili-Q estéril e filtrada)

Tabela 2. Distribuições das 41 estirpes de Staphylococcus aureus confirmadas no PCR de acordo com os pontos de colheita das amostras.

\begin{tabular}{lcc}
\hline Ponto de colheita em micro-usina estudada & $\mathrm{n}$ & $\%$ \\
\hline Superfície do interior do latão de leite recebido dos produtores & 2 & $(51,52)$ \\
\hline Superfície do tanque de recepção & 3 & 7,3 \\
\hline Leite cru do tanque de recepção & $(10,11,22)$ & 7,3 \\
\hline Superfície do tanque de estocagem & $(1,2,12,13,14,23)$ & 14,6 \\
\hline Leite cru do tanque de estocagem & 5 & 12,2 \\
\hline Superfície do tanque de equilíbrio do leite pasteurizado & $(3,4,24,25,35)$ & 5 \\
\hline Leite pasteurizado para elaboração do queijo & $(5,6,15,16,26)$ & 12,2 \\
\hline Superfície do cortador da massa do queijo & 3 & 7,3 \\
\hline Superfície da mesa utilizada na elaboração do queijo & $(27,28,47)$ & 3 \\
\hline Superfície do tambler de elaboração do queijo & $(48,49,53)$ & 7,3 \\
\hline Mãos do manipulador & $(21)$ & 2,5 \\
\hline Queijo embalado para comercialização & 1 & 2,5 \\
\hline TOTAL & $(29)$ & 1,3 \\
\hline
\end{tabular}




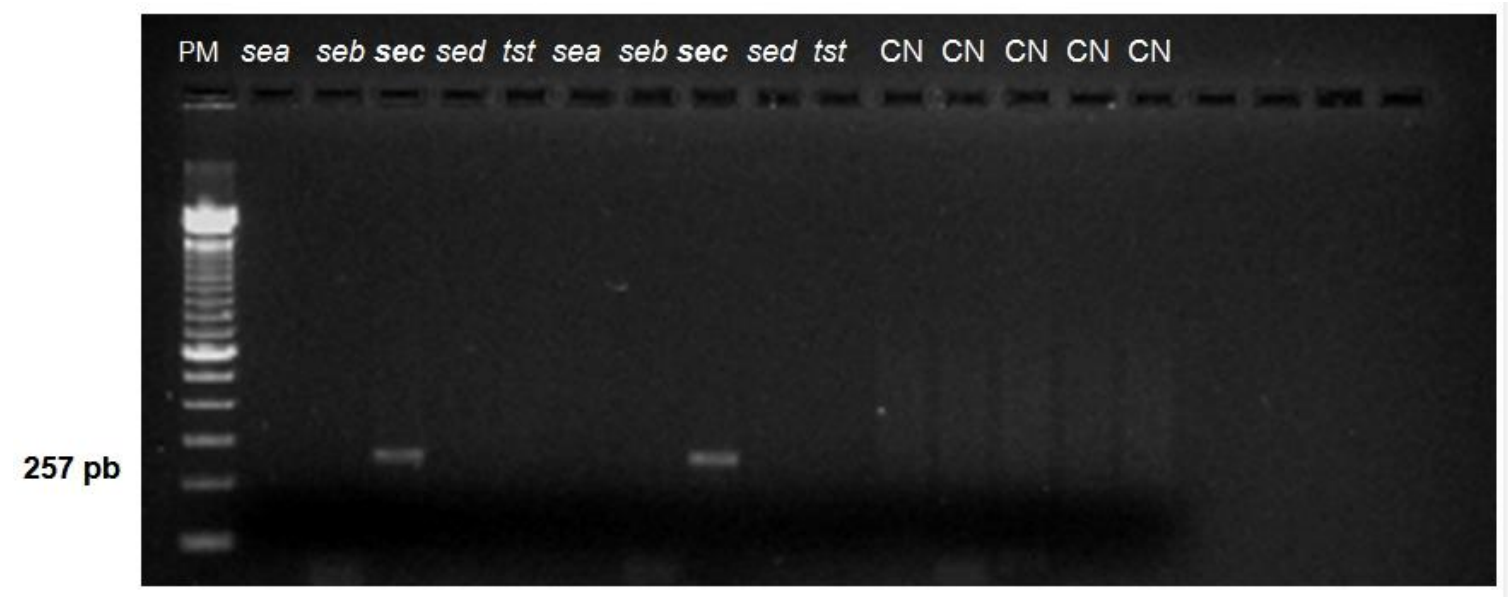

Figura 2. O produto da reação de amplificação de algumas amostras submetidas à análise molecular para confirmação das estirpes de Staphylococcus aureus com enterotoxinas SEA, SEB, SEC, SED e a TSST - 1. PM: Marcador de Peso Molecular Ladder 100 (Invitrogen®); CN: Controle Negativo (utilização de água Mili-Q estéril e filtrada)

Tabela 3. Distribuições das 25 estirpes de Staphylococcus aureus confirmadas no PCR como toxigênicas de acordo com os pontos de colheita das amostras

\begin{tabular}{|c|c|c|}
\hline Ponto de colheita em micro-usina estudada & $\begin{array}{l}\mathrm{n} \\
\text { (amostra) } \\
\text { (tipo de toxina) }\end{array}$ & $\%$ \\
\hline Superfície do interior do latão de leite recebido dos produtores & $\begin{array}{l}2 \\
(51,52) \\
(\text { sea }, \text { sea })\end{array}$ & 8,0 \\
\hline Superfície do tanque de recepção & $\begin{array}{l}1 \\
(22) \\
(\text { sea })\end{array}$ & 4,0 \\
\hline Leite cru do tanque de recepção & $\begin{array}{l}3 \\
(1,14,23) \\
(\text { sec }, \text { seb }, \text { sea })\end{array}$ & 12,0 \\
\hline Superfície do tanque de estocagem & $\begin{array}{l}3 \\
(3,24,35) \\
(\text { sea/sec,sec,sea })\end{array}$ & 12,0 \\
\hline Leite cru do tanque de estocagem & $\begin{array}{l}2 \\
(6,26) \\
(\text { sea,sea })\end{array}$ & 8,0 \\
\hline Superfície do tanque de equilíbrio do leite pasteurizado & $\begin{array}{l}2 \\
(27,47) \\
(\text { sea }, \text { sea })\end{array}$ & 8,0 \\
\hline Leite pasteurizado para elaboração do queijo & $\begin{array}{l}3 \\
(48,49,53) \\
(\text { seb/sec, sea,sea })\end{array}$ & 12,0 \\
\hline Superfície do cortador da massa do queijo & $\begin{array}{l}1 \\
(21) \\
\text { (sea) }\end{array}$ & 4,0 \\
\hline Superfície do tambler de elaboração do queijo & $\begin{array}{l}1 \\
(56) \\
(\mathrm{sec})\end{array}$ & 4,0 \\
\hline Mãos do manipulador & $\begin{array}{l}4 \\
(7,17,18,74) \\
(\text { sea/seb }, \text { seb,sea,sec })\end{array}$ & 16,0 \\
\hline Queijo embalado para comercialização & $\begin{array}{l}3 \\
(19,20,69) \\
\text { (sea/tsst, sea, sec) }\end{array}$ & 12,0 \\
\hline TOTAL & 25 & $100 \%$ \\
\hline
\end{tabular}


Os pontos de colheita de amostras que apresentaram maior frequência de isolamento de estirpes de Staphylococcus aureus foram as mãos do manipulador $(19,5 \%)$, leite cru do tanque de recepção $(14,6 \%)$, tanque de expansão de estocagem do leite cru $(12,2 \%)$ e o leite cru do tanque de estocagem $(12,2 \%)$.

Dentre as 41 estirpes de Staphylococcus aureus, foi amplificado o DNA cromossômico específico de algumas das enterotoxinas SEA, SEB, SEC, SED e a TSST - 1 em 25 amostras (Tabela 3). $\mathrm{O}$ produto da reação de amplificação de algumas amostras submetidas à análise molecular para confirmação das estirpes de Staphylococcus aureus com a presença de enterotoxinas SEA, SEB, SEC, SED e a TSST - 1 está apresentado na Figura 2.

Com relação aos resultados da presença dos genes das enterotoxinas e toxina TSST-1 em 25 amostras, pode,-se observar na Tabela 314 amostras compositividade para o gene da enterotoxina SEA (56\%), duas amostras com positividade para o gene SEB (8\%), cinco amostras com positividade para o gene da enterotoxina SEC (20\%), uma amostra apresentando positividade para os genes das enterotoxinas SEA e SEC (4\%), uma amostra apresentando positividade para os genes das enterotoxinas SEB e SEC (4\%), uma amostra apresentando positividade para os genes das enterotoxinas SEA e SEB (4\%) e uma amostra apresentando positividade para os genes da enterotoxina SEA e da toxina TSST-1(4\%). Os pontos de colheita que apresentaram maior frequência de isolamento de estirpes de Staphylococcus aureus toxigênico foram: as mãos do manipulador $(16,0 \%)$, leite cru do tanque de recepção $(12,0 \%)$, superfície do tanque de estocagem do leite cru $(12,0 \%)$, leite pasteurizado para elaboração do queijo (12,0\%) e o queijo Minas frescal pronto para consumo $(12,0 \%)$.

\section{DISCUSSÃO}

A simples presença de amostras toxigênicas de Staphylococcus aureus no queijo não implica na ocorrência de intoxicações, porém o risco existe principalmente se se considerar que esse microrganismo é o mais envolvido nas infecções intramamárias dos bovinos, que o leite é um excelente meio para o desenvolvimento do Staphylococcus aureus e que pequenas concentrações de toxinas são suficientes para causar doença em seres humanos, principalmente em crianças e idosos (BORGES et al., 2008; CONTRERAS \& RODRÍGUEZ, 2011)

Observa-se, na Tabela 3, a prevalência dos genes sea de forma particular em 56,0\% das estirpes que apresentaram a amplificação de pelo menos um gene. A detecção do gene da enterotoxina A em linhagens de Staphylococcus aureus é importante, visto que a SEA é tóxica em baixas concentrações (BORGES et al., 2008). No entanto, não foram encontrados dados científicos que apresentassem proximidade de valores referentes ao gene sea na indústria de queijo. SCHERRER et al. (2004) verificaram, em leite de cabras obtido de tanques de expansão, a presença deste gene em 28 (14,6\%) estirpes de Staphylococcus aureus. SENGER \& BIZANE (2011), analisaram queijos Minas frescal artesanais e industrializados e verificaram que o queijo de produção artesanal apresentou contaminação por $S$. aureus superior aos padrões legais em $40 \%$ (12) das amostras, já o queijo industrial de 23,3 \% (7). Predominaram as EEA, EEB, seguida da EED para as amostras artesanais. Enquanto EEB foi predominante entre as amostras industriais.

A simples presença de genes enterotoxigênicos não indica, necessariamente, a capacidade do microrganismo de produzir toxina biologicamente ativa suficiente para induzir manifestações clínicas (MCLAUCHLIN et al., 2000). No entanto, o simples fato de uma estirpe conter um ou mais genes enterotoxigênicos deve ser significante, pois pode oferecer risco à Saúde Pública caso encontre condições favoráveis à produção de enterotoxinas.

\section{CONCLUSÕES}

O conhecimento do perfil molecular dos Staphylococcus aureus auxilia na melhor compreensão dos estudos epidemiológicos de dispersão destes patógenos na micro-usina objeto desta investigação.

Pode-se destacar a adoção de algumas medidas que devem ser seguidas durante a elaboração do queijo Minas frescal na micro-usina estudada: maior cuidado com a limpeza e desinfecção dos equipamentos; cuidados com a qualidade da matéria-prima recebida; aumento da frequência de higienização das mãos dos manipuladores e a utilização obrigatória de luvas durante a manipulação do queijo.

O conhecimento da presença de estirpes de Staphylococcus aureus de potencial toxigênico corrobora para um cuidado maior na elaboração do queijo Minas frescal eliminando a possibilidade de casos de intoxicação alimentar.

\section{AGRADECIMENTOS}

À FAPESP pelo auxílio financeiro e ao 
ITAL pelo incentivo científico.

\section{REFERÊNCIAS}

AMERICAN PUBLIC HEALTH ASSOCIATION. Committee on Microbiological Methods for Foods. Compendium of methods for the microbiological examination of foods. 3. ed. Washington: American Public Health Association, 1219p. 2001.

BORGES, M. F., ARCURI, E. F.; PEREIRA, J. L.; FEITOSA, T.; KUAYE, A. Y. Staphylococcus enterotoxigênicos em leite e produtos lácteos, suas enterotoxinas e genes associados: revisão. Boletim do Centro de Pesquisa de Processamento de Alimentos, v. 26, n. 1, p. 70-86, 2008.

BRITO, M. A. V. P.; BRITO J. R. F.; SOUZA, H. M.; VARGAS, O. L. Avaliação da sensibilidade da cultura de leite do tanque para isolamento de agentes contagiosos da mastite bovina. Pesquisa Veterinária Brasileira, v.18, n.1, p.39-44, 1998.

CARMO, L. S.; DIAS, R. S.; LINARDI, V. R.; SENA, M. J. ; SANTOS, D. A.; FARIA, M. E. ; PENA, E. C.; JETT, M.; HENEINE, L. G. Food poisoning due to enterotoxigenic strains of Staphylococcus present in Minas cheese and raw milk in Brazil. Food Microbiology, v. 19, p. 9-14, 2002.

CONTRERAS, G.A.; RODRÍGUEZ, J.M. Mastitis: comparative etiology and epidemiology. Journal of Mammary Gland Biology and Neoplasia, v.16, p.339356, 2011.

CUNHA, M. L. R. S.; CALSOLARI, R. A. O.; ARAÚJO JÚNIOR, J. P. Detection of enterotoxin and Toxic Shock Syndrome Toxin 1 genes in Staphylococcus, with emphasis on coagulase-negative Staphylococci. Microbiology and Immunology, v. 51, n. 4, p. 381-390, 2007.
MacFADDIN, J. F. Biochemical tests for identification of medical bacteria. 2ed. Baltimore: Willians e Wilkins, 1980. 527p.

MARTINEAU, F.; PICARD, F. J.; ROY, P. H.; OUELLETTE, M.; BERGERON, M. G. Species-specific and ubiquitous-DNA-based assays for rapid identification of Staphylococcus aureus. Journal of Clinical Microbiology, v.36, n.3, p.618-623, 1998.

MEDEIROS, M. I. M. Epidemiologia molecular aplicada ao estudo de estirpes de Staphylococcus aureus na produção de queijo tipo Minas frescal. 2011. 70f. Tese (Doutorado em Medicina Veterinária) Universidade Estadual Paulista "Júlio de Mesquita Filho" - Faculdade de Ciências Agrárias e Veterinárias - Campus de Jaboticabal, 2011. Disponível em http://acervodigital.unesp.br/handle/123456789/62995,

Acesso em fevereiro de 2013.

MCLAUCHLIN, J.; NARAYANAN, G. L.; MITHANI, V.; O'NEILL, G. The detection of enterotoxins and toxic shock syndrome toxin genes in Staphylococcus aureus by polymerase chain reaction. Journal of Food Protection, Des Moines, v. 63, p. 479-488, 2000.

QUINTANA, R. C.; CARNEIRO, L. C. Avaliação das condições higiênicosanitárias dos queijos minas frescal e mussarela produzidos na cidade de Morrinhos- GO. Revista Brasileira de Saúde e Produção Animal, v. 8, n.3, p. 205-211, 2007.

SCHERRER, D.,CORTI, S.; Muehlherr, J.E.; Zweifel, C.; Stephan, R. Phenotypic and genotypic characteristic of Staphylococcus aureus isolated from raw bulk-tank milk samples of goats and sheep. Veterinary Microbiology, v.1, p. 101-107, 2004.

SENGER, A. E. V.; BIZANI D. Pesquisa de Staphylococcus aureus em queijo Minas frescal, produzido de forma artesanal e industrial, comercializado na cidade de Canoas/RS, Brasil. Revista de Ciências Ambientais, v.5, n.2, p. 25-42, 2011.

Protocolado em: 08 jul. 2011. Aceito em 23 jan. 2013. 